\title{
Bone cement modeling for percutaneous vertebroplasty
}

\author{
Nicole Lepoutre, Laurence Meylheuc, Gabriela luliana Bara, Laurent Barbé, Bernard Bayle \\ ICube University of Strasbourg UMR 7357 CNRS INSA Strasbourg, 1 place de I'Hôpital, 67091, Strasbourg, France
}

\begin{abstract}
Vertebroplasty procedures provide a significant ben efit for patients suffering from vertebral fractures. In order to address current issues of vertebroplasty procedures, an injec tion device able to control the bone cement viscosity has been developed. In addition, this device allows to protect the practi tioner by removing him/her from the $X$ rays area. In this con text, a study is first proposed to quantify the bone cement viscosity during its polymerization reaction on a rotational rhe ometer. These experimental measurements have led to the identification of a complete behavior law that takes into account the simultaneous effects of shear rate, time, and
\end{abstract}

\section{INTRODUCTION}

\section{Medical context}

Vertebral compression fractures are characterized by a collapse of the vertebral body, leading to a decrease in the vertebral height but also to a critical modification of the physiological curvatures. These fractures are associated with severe pain and worsen heavily the quality of life and the abilities of the victims. ${ }^{1}$ As an alternative to long conservative treatments, percutaneous vertebroplasty, introduced in $1984,{ }^{2}$ strengthens the pathological vertebra by injecting synthetic bone cement through a trocar under X-ray guidance (Figure 1). Acrylic bone cements are the most frequently used materials for percutaneous vertebroplasty because of their mechanical strength and cost effectiveness. Commonly named PMMA, these cements result from the manual or mechanical mixing of a sterile polymer powder and of a liquid component, starting an exothermic polymerization reaction. The cement viscosity increases all along the injection until the bone cement becomes solid and consolidates the vertebral body.

Despite immediate and significant patients' pain relief $\mathrm{f}^{3-5}$ and mobility increase, ${ }^{6}$ the permanent practitioners' exposure to harmful X-rays during the injection restricts this very promising intervention. Moreover, cement leakage outside the treated vertebra is quite critical (up to $20 \%)^{7}$ and may cause complications from a simple lumbar pain to a pulmonary embolism. However, it is symptomatic in only around $1.6 \%$ of the performed vertebroplasty procedures. ${ }^{8}$ Right temperature. Based on this preliminary study, this article finally aims to prove the ability of estimating the viscosity of the flowing bone cement on the developed injection system. A final set of experiments validates that the injection device dedicated to vertebroplasty procedures can control the flowing bone cement viscosity by acting on the temperature.

Key Words: percutaneous vertebroplasty, acrylic bone cement, viscosity modeling, injection device

after the mixing process, the cement viscosity is very low, which increases the risk for potential leakage outside the vertebra. Then, the cement hardens quickly because of the ongoing polymerization reaction. Between these two states, the radiologist has only a short working time of about $10 \mathrm{~min}$ in order to perform the cement injection and to remove the needle. Therefore, the viscosity estimation and its control during the injection procedure are the key factors in leakage management ${ }^{9}$ that remains fully subjective with the tools currently available in vertebroplasty.

Within this medical framework, our new injection device technologically detailed in Refs. 10,11 addresses the above mentioned drawbacks by keeping the practitioner away from the X-ray area while offering an appropriate viscosity control aiming to reduce cement leakage risks ${ }^{12}$ and to lengthen the injection phase. However, the development of control strategies for our injection device requires both the understanding of the bone cement behavior during its polymerization reaction and the identification of a rheological behavior law suitable for control purposes. These are the objectives of the present article.

\section{Bone cement rheological properties}

Orthopedic bone cements have a highly non-Newtonian behavior. An overview of the studies outlining this behavior emphasizes three main parameters influencing the evolution of bone cement viscosity: shear rate, time and temperature. The shear rate is a significant factor ${ }^{13,14}$ : the higher the 

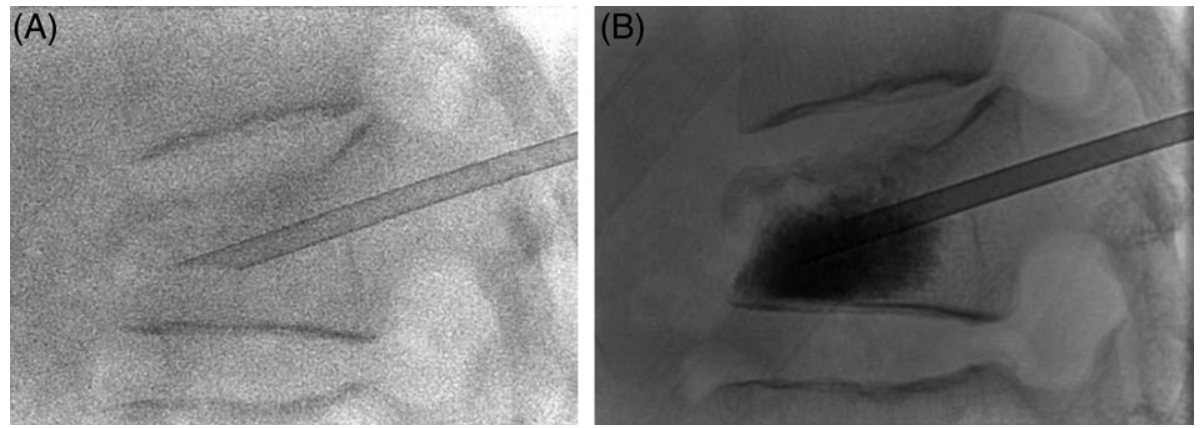

FIGURE 1. Lateral fluoroscopic images of a vertebroplasty procedure: (A) after the insertion of the trocar and (B) after the injection of bone cement inside the damaged vertebra.

shear rate is, the lower the viscosity is. This shear-thinning behavior is extended during the mixing process: mixing under oscillations significantly lowers the viscosity. ${ }^{15}$ Since bone cement undergoes a polymerization reaction, its viscosity is time-dependent as also confirmed by Krause et al. ${ }^{16}$ and by Lewis and Carroll ${ }^{17}$ on various acrylic bone cements. The last factor significantly influencing the cement viscosity is the temperature. Increasing the temperature accelerates the polymerization reaction and, therefore, generates a faster viscosity increase and a shorter working time, as reported in Refs. 18,19 for acrylic cements. In addition, the study presented by Sullivan and Topoleski ${ }^{20}$ shows the same influence of the initial temperature of the components (powder and liquid) on the bone cement working time.

\section{Viscosity modeling}

A realistic rheological model is needed for the computation of the cement viscosity on our device named S-Tronic (see "Description of the device" section for more details), called online viscosity in this article. As far as we know, despite an abundant literature outlining the time-dependent viscosity characteristics, $^{21-24}$ there is no complete rheological model considering all three dependencies (shear rate, time, and temperature).

Note that, according to the literature dealing with the modeling of bone cement viscosity, the shear-thinning behavior of bone cements has often been neglected as pointed out in Refs. 15,25. This introduces a rough approximation since the inner diameter of the cannula guiding the bone cement flow during a normal vertebroplasty procedure generates such shear rates (up to $100 / \mathrm{s}$ ) that bone cement viscosity can decrease by more than one decade on a logarithmic scale. ${ }^{22}$ The most widespread model for characterizing shear-thinning fluids, the Ostwald-de Waele law, ${ }^{26}$ has also been used for modeling acrylic bone cements. This law, commonly called power law, shows the following relationship between viscosity $\eta$ and shear rate $\dot{\gamma}$ :

$$
\eta(\dot{\gamma}, t)=K(t) \dot{\gamma}^{n(t)} 1
$$

where $K$ represents the flow consistency in $\mathrm{Pa} s^{n}$ and $n \in[0 ; 1]$ is the flow index of the sample. In order to express the time dependency, some authors supposed $n$ and $K$ to be linear or exponential functions of time ${ }^{16,21}$ where the zero initial instant is the beginning of the mixing phase. The Carreau-Yasuda law ${ }^{27,28}$ has been employed in Ref. 29 for characterizing the shear-thinning behavior of acrylic bone cements. This model, in comparison with the power law, presents a Newtonian plateau at low shear rates and a horizontal asymptote at infinite shear rates.

Regardless of the exothermic nature of the polymerization reaction, the correlation between temperature and viscosity increase can lead to a relationship connecting explicitly time and temperature. Usually, the well-known Arrhenius law allows to describe this relationship. ${ }^{30,31}$ For instance, in Ref. 18 and, later, in Ref. 32, authors expressed the bone cement temperature dependence as

$$
\frac{1}{t_{\mathrm{v}}}=A \exp \left(\frac{-E}{R_{\mathrm{gas}} T}\right)
$$

where $t_{\mathrm{v}}$ is the time required to reach a given viscosity, $R_{\text {gas }}$ the gas constant and $T$ the temperature of the sample. The activation energy $E$ and the constant $A$ are parameters to be identified, as achieved by Farrar and Rose based on measurements provided by a rotational rheometer with a parallel plate geometry. ${ }^{18}$

From the previous state of the art, the bone cement behavior can be characterized qualitatively as shear-thinning, time and temperature dependent. To our knowledge, there is no rheological model in the literature describing the bone cement viscosity evolution according to all these three extrinsic parameters. The contributions of the present article are diverse. First, a set of viscosity measurements are performed on a rotational rheometer to outline the dependency of the cement viscosity with shear rate, time and temperature. Then, these measurements are analyzed in order to identify a new viscosity model that accounts for all these three dependencies. Finally, this model is extended to the online estimation of the bone cement viscosity by using our injection device as a capillary rheometer.

\section{MATERIALS AND METHODS}

\section{Materials}

Despite that several acrylic bone cements have been evaluated (see "Rheological study" section), the complete 
rheological study has only been performed on the commercial low-viscosity bone cement Osteopal ${ }^{\circledR} \mathrm{V}$ from Heraeus. Each single kit provides a cement volume of around $12 \mathrm{~mL}$. This acrylic cement has been chosen based on the current practice of our clinical partner, the department of interventional imaging of the University Hospital of Strasbourg, in which approximately 2500 vertebrae are treated per year. As most acrylic bone cements, it consists in a sterile twocomponent system composed of a polymeric powder and a monomeric liquid. The liquid component consists mainly of Methyl MethAcrylate (MMA). Besides $9.2 \mathrm{~g}$ of MMA, $0.2 \mathrm{~g}$ of the co-initiator dimethyl-para-toluidine is a part of the activation triggering the radical polymerization. ${ }^{33}$ Finally, to prevent premature polymerization from exposure to light or high temperature during storage, a very small amount of HydroQuinone stabilizes the liquid monomer. In the polymeric powder, the main component (14.2 g) is prepolymerized poly(MMA) (PMMA). This powder incorporates $0.1 \mathrm{~g}$ of benzoyl peroxide as initiator, encouraging the polymerization at room temperature. Since bone cement needs to be visible on fluoroscopic images, a radiopacifier (zirconium dioxide) is combined with the polymer powder. The powder as well as the liquid contain a coloring agent, chlorophillin E141, giving a green color to the bone cement.

\section{Viscosity identification on a rotational rheometer} Viscosity measurement by oscillations. While a capillary rheometer provides measurements of steady shear functions, rotational rheometers allow to study the viscoelastic properties of a material and to compute its complex viscosity by applying small deformations with alternating stress. Meanwhile, unlike a capillary one, a rotational rheometer easily allows to control the sample temperature since the volume of the tested material is low (around $1 \mathrm{~mL}$ ). Therefore, a rotational rheometer with a parallel-plate geometry has been selected to characterize and model the complex behavior of the bone cement. It consists of two parallel plates of radius $R$, spaced by a gap of size $h$, restraining the fluid sample. The bottom plate is fixed while the upper one applies the stress by rotating.

The controlled-rate mode has been preferred to the controlled-stress mode for repeatability concerns. The loaded sample is subjected to a sinusoidal strain $\gamma(t)=\gamma_{0} \sin \omega t$ with $\omega$, a constant angular frequency, and $\gamma_{0}$, a small amplitude. For small deformations, the linear viscoelastic response results in a shear stress $\tau(t)=\tau_{0} \sin (\omega t+\delta)$ phase-shifted by an angle $\delta$, called loss angle. The complex viscosity $\eta^{*}$ is defined as the ratio between the complex shear stress $\tau^{*}$ and the complex shear rate $\dot{\gamma}^{*}$ yielding:

$$
\eta^{*}(\omega)=\frac{\tau^{*}}{\dot{\gamma}^{*}}=\frac{\tau_{0}}{\omega \gamma_{0}}(\sin \delta-j \cos \delta)
$$

This complex viscosity can directly be linked to the steady-shear viscosity measured as a function of shear rate through the Cox-Merz rule exposed in Refs. 30,31. This empirical rule has been found valid for most molten polymers and states that $\left|\eta^{*}(\omega)\right|=\eta(\dot{\gamma}) \mid$ for $\omega=\dot{\gamma}$. In the following, we assume that this law is valid for orthopedic bone cements as already considered in the literature. ${ }^{17,34,35}$ During the experiments, separate temperature and a frequency controls enable to disconnect the thermal and the shearthinning effects.

Experimental set-up. Our experiments have been carried out on the parallel-plate rotational rheometer HAAKETM

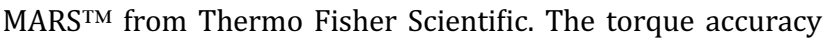
is $0.2 \mu \mathrm{N} \mathrm{m}$ and the normal force accuracy is $5 \mathrm{mN}$. According to Thermo Fisher Scientific evaluation, the measured deviation of viscosity is less than $1 \%$. Radius of both plates has been fixed to $R=10 \mathrm{~mm}$ while the gap size is $h=1 \mathrm{~mm}$. The sample is temperature-controlled by Peltier modules located below the lower plate of the rheometer and the maximum heating/cooling rate of the controlled chamber is $20 \mathrm{~K} / \mathrm{min}$. The thermal power of these modules allows to prevent the exothermic reaction that undergoes bone cement. Note that, ex vivo, bone cement can reach $100^{\circ} \mathrm{C}$. Conditions under which our experiments have been conducted are close to those of any intervention performed at the department of Interventional Radiology at the University Hospital of Strasbourg. The cement kits have all been stored in a refrigerator at $4 . \mathrm{C}$ and the room has been airconditioned at $22^{\circ} \mathrm{C}$.

The rheometer is delivered with the RheoWin software to control the device. Before starting, the sample reference temperature and the amplitude and the frequency of the deformation must be indicated. The amplitude $\gamma_{0}$ has been set at 0.5 for all experiments in order to stay in the linear viscoelastic domain. ${ }^{36}$

After zeroing the rheometer, a bone cement kit composed of a powder pack and a liquid ampoule is taken out of the refrigerator. Then, a chronometer is triggered simultaneously with the beginning of the hand-mixing phase of both components in a bowl. This mixing phase lasts around $40 \mathrm{~s}$ until a homogeneous paste is obtained. A small sample of cement is finally loaded on the fixed plate of the rotational rheometer before the rotating shaft is lowered to meet the required gap $h$. Oscillations and viscosity computations start at this same instant. Simultaneously, a viscosity curve function of time is updated as torque measurements are available. The sample analysis ends whenever the viscosity reaches a maximal value $\left(5.10^{5} \mathrm{~Pa} \mathrm{~s}\right)$ or whenever the device cannot manage the deformation set point anymore.

Identification of the power law. As conceded by many works in the literature, acrylic bone cement is assumed to follow the power law defined by Eq. 1. With $n<1$, Eq. 1 describes the shear-thinning behavior of acrylic bone cement. This simple model with two constant parameters remains relatively close to the real behavior and is easy to identify. This rheological model provides a description of the bone cement behavior considering the main extrinsic parameters and will also serve as a benchmark for online viscosity measurements carried out on the injection device. 

ten as

By applying the logarithmic function to Eq. 1 can be writ-

$$
\log (\eta)=\log (K)+(n-1) \log (\dot{\gamma})
$$

Therefore, a linear regression between $\log (\eta)$ and $\log (\dot{\gamma})$ variables allows to identify parameters $n$ and $K$. The slope determines $n-1$ while $\log (K)$ is evaluated with the $y$-intercept. Repeating this optimization at different times allows to plot $n$ and $K$ over time.

Temperature influence. Note that the power law model does not take into account the temperature influence. Usually applied for melt polymers, ${ }^{30,31}$ the time-temperature superposition principle states that a temperature change between a reference temperature $T_{\text {ref }}$ and any temperature $T$ is equivalent to a double (horizontal and vertical) shifting of the viscosity through the translation coefficient $a_{T_{\text {ref } \rightarrow T}}$ :

$$
\eta(\dot{\gamma}, T)=\frac{1}{a_{T_{\mathrm{ref}} \rightarrow T}} \eta\left(\frac{\dot{\gamma}}{a_{T_{\mathrm{ref}} \rightarrow T}}, T_{\mathrm{ref}}\right)
$$

Identifying this translation coefficient is difficult since data have not been acquired for a large and continuous range of shear rates. Therefore, in the following, this wellknown principle is adapted in order to switch from a viscosity evolution curve at temperature $T_{\text {ref }}$ to another one at $T$ and at a fixed shear rate $\dot{\gamma}$. Indeed, a focus on the acquired data shows that a double shift factor can still be considered. For a temperature change from $T_{\text {ref }}$ to $T$ at a fixed $\dot{\gamma}$, not only the time scale is adjusted but also the viscosity is shifted by a vertical translation factor as schematized in Figure 2. In other words:

$$
\eta\left(\dot{\gamma}, a_{T_{\mathrm{ref} \rightarrow T}} t, T\right)=b_{T_{\mathrm{ref} \rightarrow T}} \eta\left(\dot{\gamma}, t, T_{\mathrm{ref}}\right)
$$

where $a_{T_{\text {ref } \rightarrow T}}>1$ and $b_{T_{\text {ref } \rightarrow T}}<1$ if $T_{\text {ref }}>T$. These inequalities express that the increase in temperature amounts to

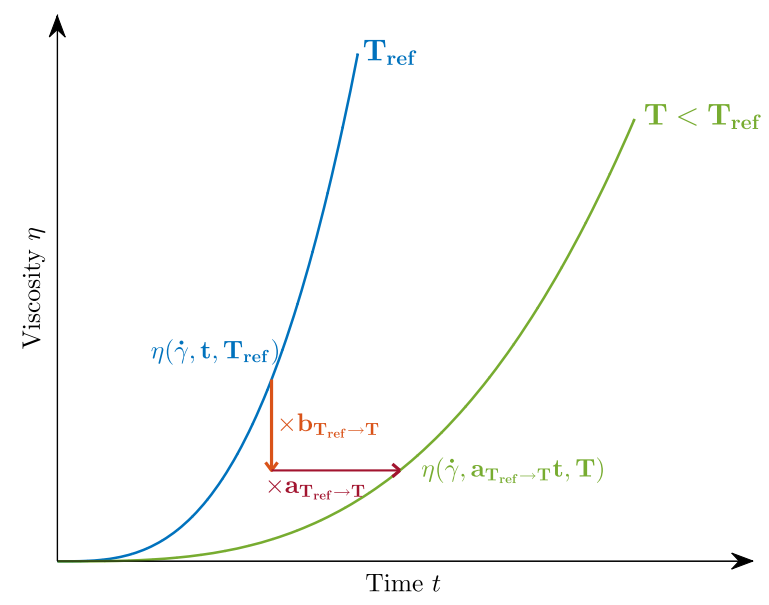

FIGURE 2. Viscosity curves at $T_{\text {ref }}$ and $T<T_{\text {ref }}$ illustrating the idea of the double shift factor. accelerating the viscosity variation rate. Conversely, decreasing the cement temperature slows down the polymerization reaction and lengthens the working phase.

At each temperature $T_{i}$ of the set $\{10 ; 15 ; 17 ; 20 ; 23 ; 25$; $37\}^{\circ} \mathrm{C}$, parameters $a_{T_{\text {ref } \rightarrow T_{i}}}$ and $b_{T_{\text {ref } \rightarrow T_{i}}}$ have been identified by solving the following optimization problem:

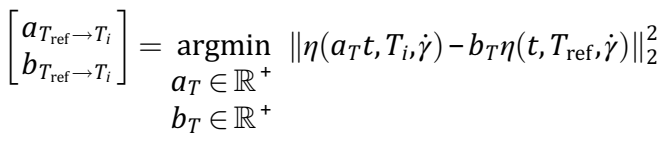

where $T_{\text {ref }}=20^{\circ} \mathrm{C}$. This curve fitting problem has been solved by applying a nonlinear least-squares solver, developed with MATLAB ${ }^{\circledR}$ using the Levenberg-Marquardt.

\section{Viscosity estimation on the S-Tronic device}

Description of the device. The S-Tronic device is a robotic assistant dedicated to the injection of bone cement inside the damaged vertebra. It provides the practitioner with an enhanced control while being at a safe distance from the Xrays source. The injection device aims to push the cement placed inside a syringe into the damaged vertebra through a cannula (Figure 3A). The injection force is measured by a $2 \mathrm{kN}$ uniaxial tension-compression sensor and used to evaluate the pressure on the piston that can reach $14 \mathrm{MPa}$. A linear position sensor has been placed on the free cart in order to provide a direct measurement of the cart. A mounting bracket allows to easily plug and remove the sheath holding the syringe filled beforehand with bone cement. Beyond $10 \mathrm{MPa}$, it occurs that syringes currently used during vertebroplasty procedures break when bone cement becomes too hard. The sheath machined out of $316 \mathrm{~L}$ stainless steel was specially designed to remove this problem.

The device further comprises a passive heat exchanger, in the sheath surrounding the syringe, and an active heat exchanger, plugged between the outlet of the syringe and the cannula. The sheath includes a eutectic mixture (Figure 3B) in order to keep the cement cold inside the syringe. Note that the ongoing polymerization reaction is irreversible and cannot be stopped. However, this passive cooling slows it down significantly and allows to provide a low viscosity cement at the input of the active heat exchanger. Experimentally, we have been able to show that Osteopal ${ }^{\circledR} \mathrm{V}$ bone cement viscosity reaches $1000 \mathrm{~Pa}$ s after $11 \mathrm{~min}$ without eutectic gel and only after $18 \mathrm{~min}$ with this passive cooling. In the "Discussion" section, the significant influence of the cement temperature inside the syringe will be discussed. The active heat exchanger consists in a central block through which flows the bone cement. Each one of the upper and lower faces of the central block is equipped with a Peltier module and a heat sink connected to a fan. A temperature control is computed in real time and is applied to the flowing bone cement. This setup allows either to heat the cement in order to reach a minimum viscosity or to cool it down in order to slow down the reaction and keep the cement viscosity low. 

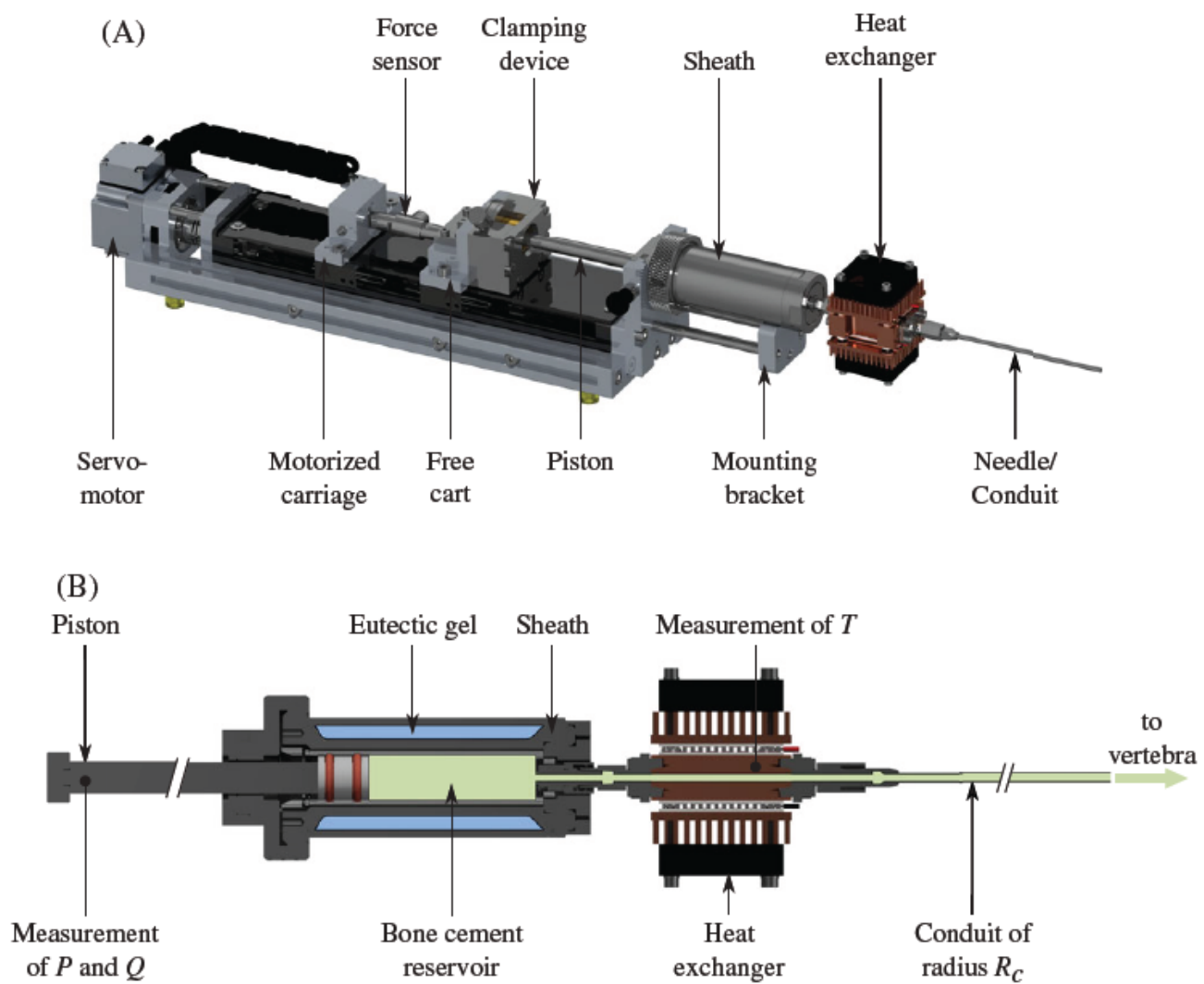

FGURE 3. Description of the S Tronic injection device: (A) CAD view of the injection device and (B) cutout drawing spotlighting the bone cement flow in green.

The complete description of the teleoperated injection device has been published in Ref. 10. Note that the teleoperation and viscosity control of the system are beyond the scope of the present publication and will not be addressed in the following.

Experimental set-up. Prior to each experiment, the cement kits were refrigerated at $4{ }^{\circ} \mathrm{C}$ to remain consistent with current vertebroplasty procedures. In addition, all the injections were performed at room temperature $T_{a}=22^{\circ} \mathrm{C}$. The usual mixing process described for the rheological measurements was always accurately replicated during the injection experiments. The prepared bone cement is poured into a $10-\mathrm{mL}$ polycarbonate syringe. Then, the filled syringe is inserted inside the sheath that is plugged onto the mounting bracket. At this point, the injection can start. Every prepared bone cement has been injected at a piston velocity $V_{P}=5 \mathrm{~mm} / \mathrm{min}$, which corresponds to a regular injection velocity during vertebroplasty. It enables to acquire results for at least $10 \mathrm{~min}$. Bone cement has been injected inside a phantom vertebra from Sawbones, either hollow or filled with a cancellous insert. For some trials, the bone cement temperature has been controlled using the heat exchanger, as shown in Figure 3.

Online viscosity estimation. The approach proposed in the following allows to estimate online the cement viscosity. It is based on the power law (1). As shown in the cutout drawing in Figure 3B, the injection flow can be assimilated to a Poiseuille flow, where the capillary is the conduit of length $L_{\mathrm{c}}$ and of radius $R_{\mathrm{c}}$ while the syringe of radius $R_{\mathrm{s}}$ filled with bone cement represents the reservoir. Thus, the principle of mass conservation coupled to the resolution of the NavierStokes equation provides the following relationship between the pressure drop $\Delta P$ and the flow rate $Q^{30}$ :

$$
Q(t)=\left(\frac{\Delta P(t)}{2 K(t) L_{c}}\right)^{\frac{1}{n(t)}} \frac{\pi n(t) R_{c}^{3+\frac{1}{n(t)}}}{3 n(t)+1}
$$

As detailed in the "Description of the device" section, the injection device is equipped with suitable instrumentation to perform the necessary measurements. The linear position sensor allows to measure the position of the carriage and, thus, to compute the bone cement flow rate $Q$. The force sensor in the transmission provides the measurement of the injection force $F$, and hence, it helps to assess the pressure drop as $\Delta P(t)=F(t) /\left(\pi R_{s}^{2}\right)-P_{\text {atm }}$. This implies the following two assumptions. On one side, the pressure at the needle outlet is supposed to be equal to the atmospheric pressure $P_{\text {atm }}$. This hypothesis will be further discussed in the "Online viscosity estimation" section. On the other side, the pressure at the outlet of the syringe is considered equal to the pressure on the plunger since the major part of the pressure 
drop occurs beyond the last cross-section reduction in a cylindrical pipe presenting different cross-section reductions. This has been confirmed by flow simulations with the ANSYS Polyflow software. Figure 4 illustrates the results for bone cement flowing at $35 \mathrm{~mm}^{3} / \mathrm{s}$ from a syringe of radius $R_{\mathrm{S}}=7.1 \mathrm{~mm}$ through a needle of length $L_{\mathrm{c}}=220 \mathrm{~mm}$ and of radius $R_{\mathrm{c}}=1.25 \mathrm{~mm}$. The inlet pressure, that is, at $z=0$, is 5.6 $\mathrm{MPa}$, and the bone cement flows out at atmospheric pressure. In this example, it can be noticed that, at the crosssection reduction $(z=120 \mathrm{~mm})$, there is only $3.3 \%$ of the total pressure drop, which motivates the previous assumption.

Despite the measurement of the pressure drop $\Delta P$ and the flow rate $Q$, Eq. 8 cannot be readily applied since the two unknown parameters $n$ and $K$ remain to be identified online, while there is only one measurement at each time step. According to the offline identification of the power law, $K$ is by far the most influencing parameter on the viscosity evolution. For the online viscosity estimation, the flow behavior

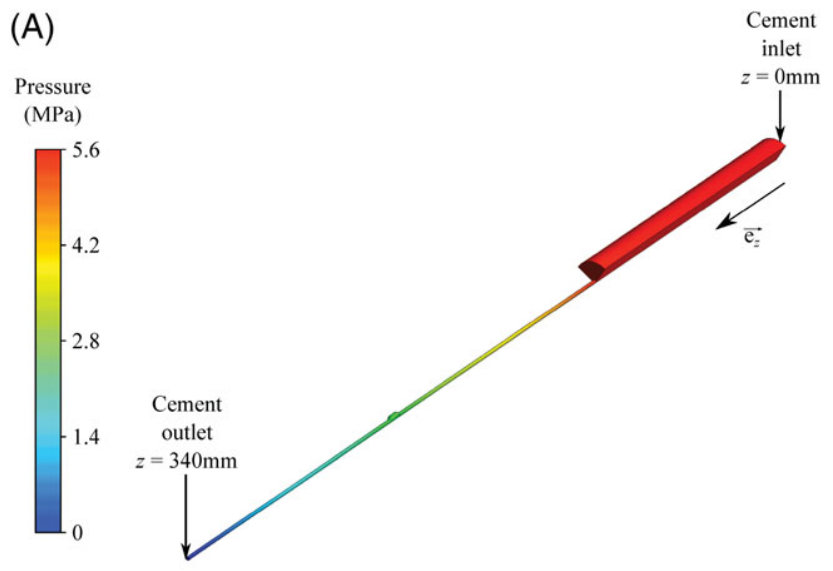

(B)

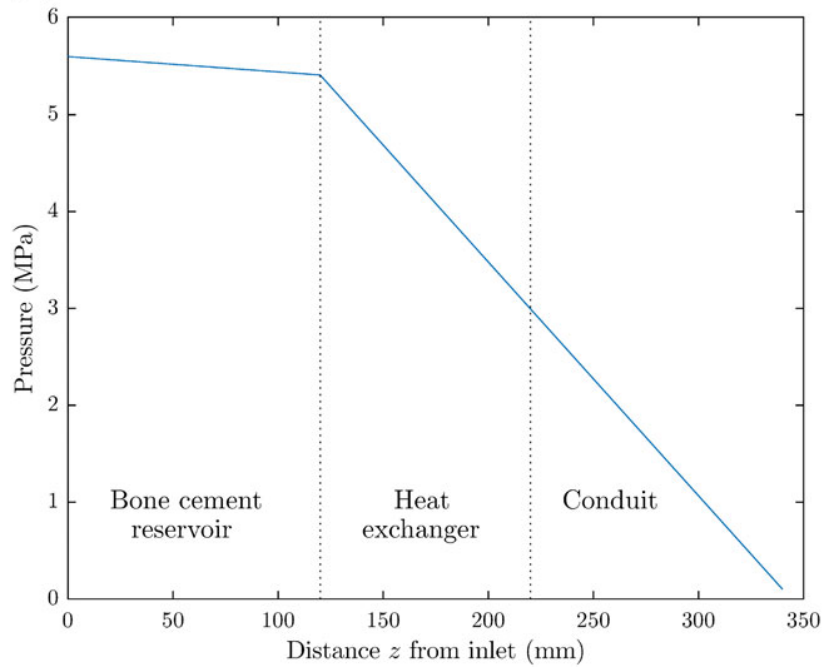

FIGURE 4. Pressure drop of flowing bone cement: (A) pressure field on a quarter of the volume and $(B)$ pressure evolution on the axis where $z=0$ is the inlet. index $n$ is supposed to be a linear function of time. Indeed, based on the rheological characterization, the identification of the power law results in the writing of $n$ as a function of time and temperature. With this hypothesis, $K$ can be computed through Eq. 8 and the appropriate instrumentation.

Viscosity is finally estimated based on Eq. 1 where, according to the framework of the medical application, the highest shear rate $\dot{\gamma}_{\omega}$, which is reached at the fluid domain wall for $r=R_{c}$, is considered:

$$
\dot{\gamma}_{\omega}=\frac{(3 n+1) Q}{\pi n R_{c}^{3}}
$$

\section{RESULTS}

\section{Rheological study}

Several series of tests have been run to characterize the effects of both temperature and shear rate. These experiments have been spread over 1 year. Over this period, we acquired 120 bone cement kits from Heraeus (Osteopal V) that were divided into 4 different batches. For each of the curves presented in Figure 5, the experiment has been repeated three times in average. The trials have featured a high repeatability with a standard deviation of about $20 \mathrm{~Pa} \dot{\mathrm{c}} \mathrm{S}$ at low viscosity $(\eta<500 \mathrm{~Pa} s)$ and about $100 \mathrm{~Pa} s$ for high viscosity $(\eta>2000 \mathrm{~Pa} \mathrm{~s})$.

During the first round of tests, the shear rate has been fixed by setting $\omega=2 \pi f$ with $f=1 \mathrm{~Hz}$, that is, $\dot{\gamma}=2 \pi / \mathrm{s}$ according to the Cox-Merz law. Then, the temperature has been incremented between successive experiments. Results are presented in Figure 5A. The temperatures range from 10 to $37^{\circ} \mathrm{C}$. The upper limit represents the body temperature, which allows to obtain information on the behavior of bone cement once injected in the treated vertebra. Temperatures below $10^{\circ} \mathrm{C}$ have not been explored since a period of $60 \mathrm{~min}$ is significantly above the radiologist expectation in terms of injection time.

A temperature $T_{0}$ has been imposed to the sample to monitor the effect of the shear rate, while the angular frequency $\omega$ has been adjusted from one trial to another by adapting the frequency $f$. In Figure 5B,C, the viscosity evolution is plotted over time for a range of shear rates at, respectively, $T_{0}=20$ and $25^{\circ} \mathrm{C}$. The selected temperatures $T_{0}$ and the tested shear rates, from $0.1 \times 2 \pi \approx 0.62 / \mathrm{s}$ to $20 \times 2 \pi \approx 125 /$ s, represent realistic injection conditions of a vertebroplasty procedure, as recorded in an interventional radiology room.

\section{Identification of the power law}

For the set of experiments at a fixed temperature displayed in Figure 5B,C, $\log (\eta)$ has been plotted as a function of $\log (\dot{\gamma})$ at each time step for curves at $T_{0}=20^{\circ} \mathrm{C}$ in Figure $6 \mathrm{~A}$ and at $T_{0}=25^{\circ} \mathrm{C}$ in Figure 6B. The obtained curves feature a linear relationship between $\log (\eta)$ and $\log (\dot{\gamma})$, which validates the use of the power law, at least in the range of shear rates chosen for our experiments and corresponding to the ones used during vertebroplasty procedures. 

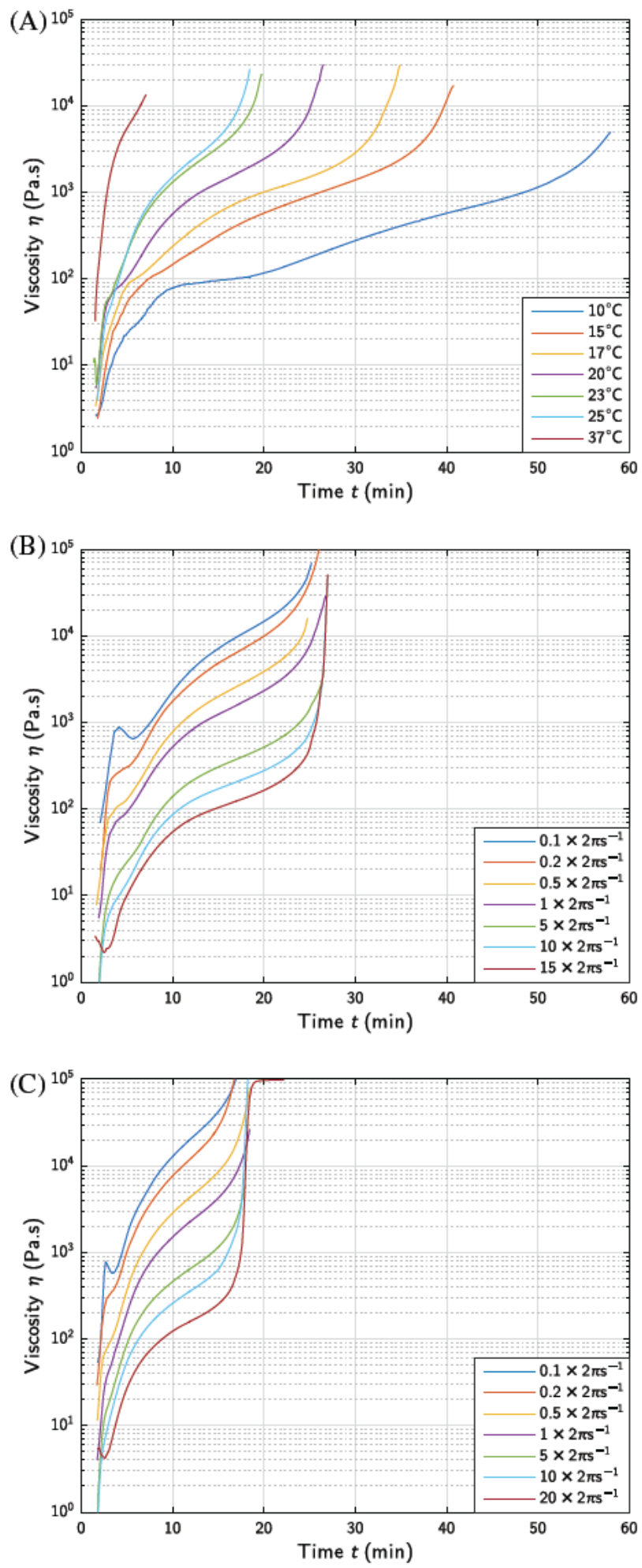

FGURE 5. Evolution of viscosity along time from mixing: (A) at $2 \pi / \mathrm{s}$ for a range of temperature from 10 to $37^{\circ} \mathrm{C}$, (B) at $T_{0}=20^{\circ} \mathrm{C}$ for several shear rates, and (C) at $T_{0}=25^{\circ} \mathrm{C}$ for several shear rates.

As explained in the "Identification of the power law" section, a linear regression has been performed to assess $n$ and $K$ for both experiments at $T_{0}=20$ and $25^{\circ} \mathrm{C}$ at time intervals $5 \mathrm{~s}$. Curves of $n$ and $K$ over time are presented in Figure 7.

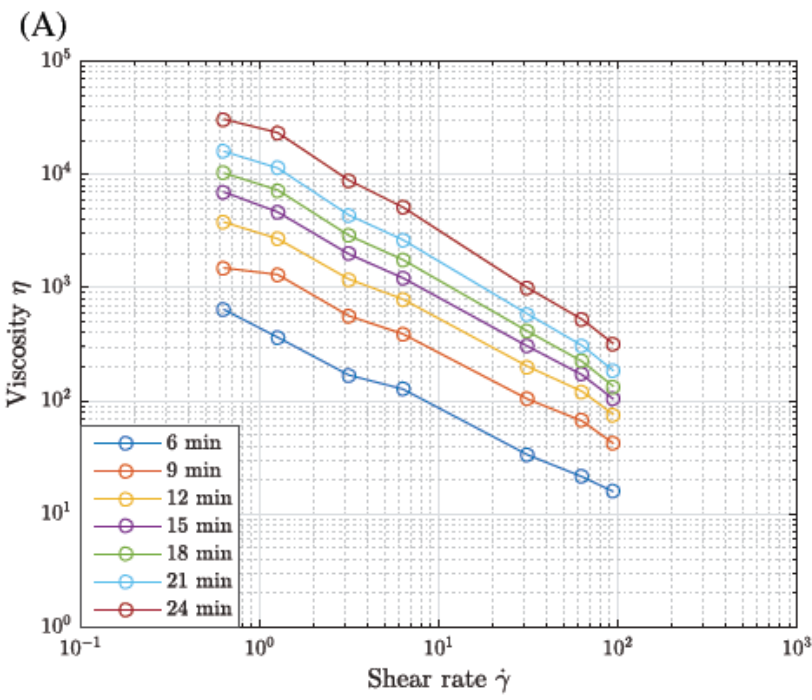

(B)

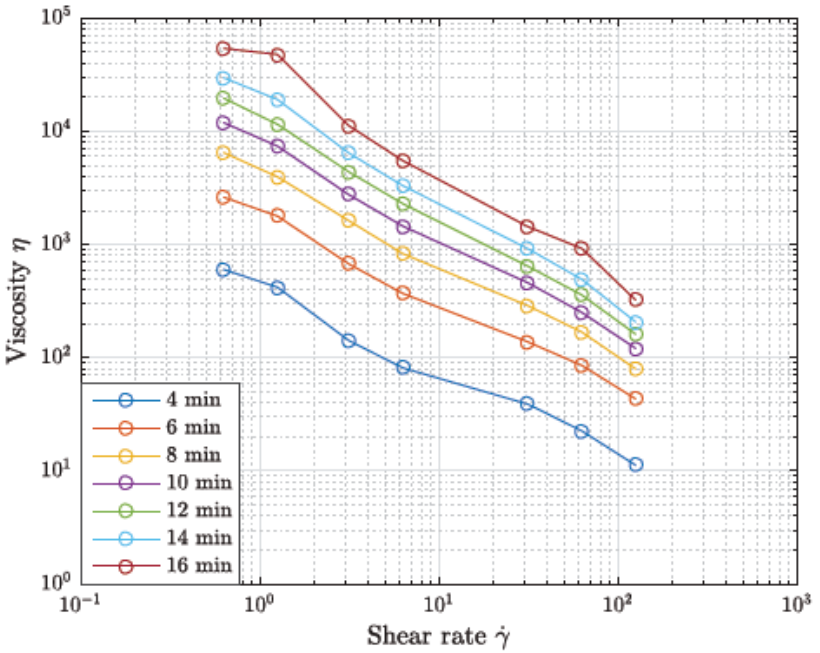

FGURE 6. Viscosity curves in logarithmic scale: (A) at $T_{0}=20^{\circ} \mathrm{C}$ and (B) at $T_{0}=25^{\circ} \mathrm{C}$.

The mean determination coefficient is $R_{\mathrm{d}}^{2}=0.9959 \pm 0.0047$ at $T_{0}=20^{\circ} \mathrm{C}$ and $R_{\mathrm{d}}^{2}=0.9924 \pm 0.0185$ at $T_{0}=25^{\circ} \mathrm{C}$.

It is important to notice that curves representing $n$ and $K$ can be identified as simple mathematical function such as linear or exponential ones. After applying a curve fitting procedure, a linear function is preferred to model the evolution of the index $n$ :

$$
n(t, T)=a_{n}(T) t+b_{n}(T)
$$

In order to parameterize the flow consistency $K$, fitting the sum of two exponential functions to the data in Figure 7B provides the best results leading to

$$
K(t, T)=a_{K}(T) \exp \left(b_{K}(T) t\right)+c_{K}(T) \exp \left(d_{K}(T) t\right)
$$

Parameters $a_{n}, b_{n}, a_{K}, b_{K}, c_{K}$ and $d_{K}$ are functions of temperature $T$, which is consistent with the temperature dependence of $n$ and $K$ noticeable in Figure 7. For $T_{0}=20$ and 

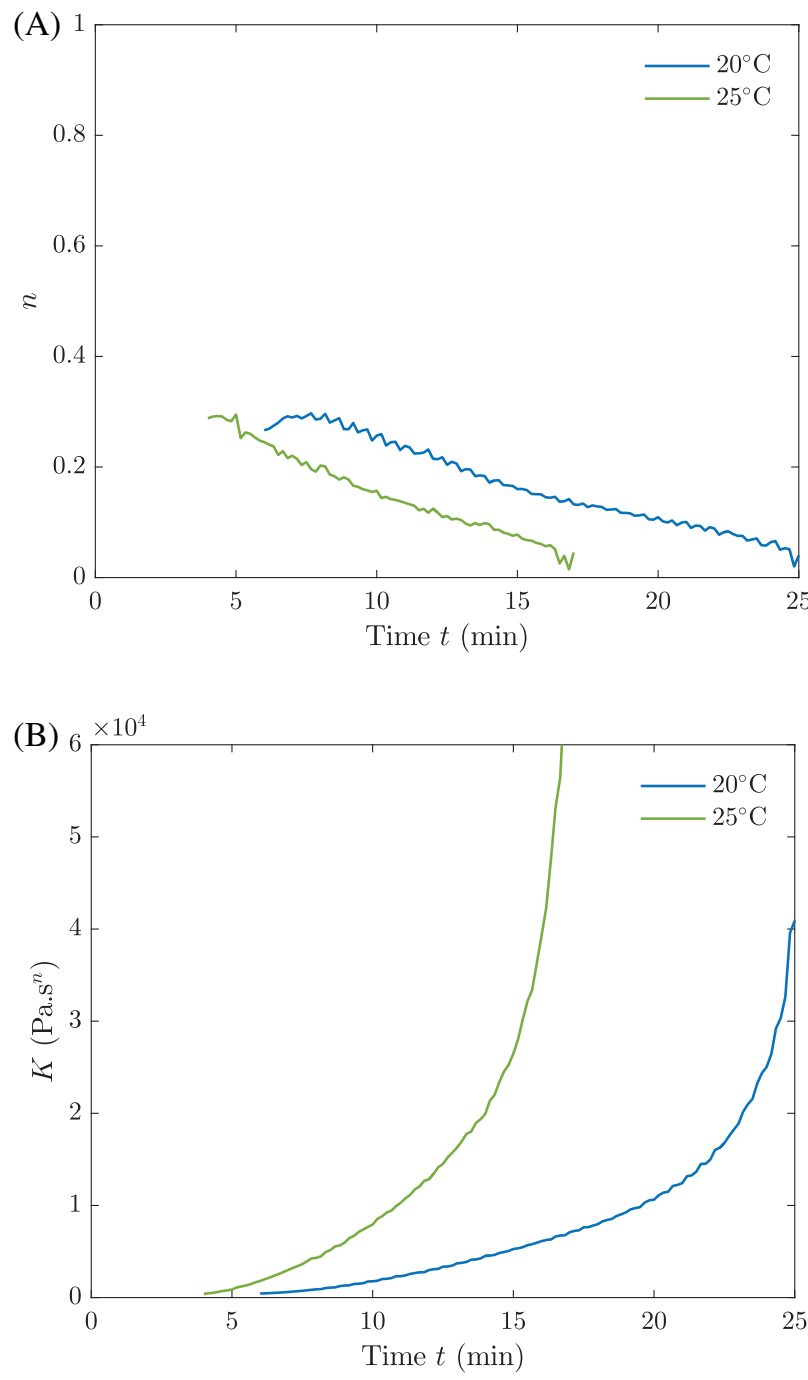

FIGURE 7. Identification of the parameters $n$ and $K$ of the power law over time at $T_{0}=20^{\circ} \mathrm{C}$ (blue curve) and at $T_{0}=25^{\circ} \mathrm{C}$ (green curve).

$25^{\circ} \mathrm{C}$, the identified parameters are provided in Table I. One can notice that the value of $a_{n}$ confirms the minor negative slope of $n$. Fitting the sum of two exponential functions to the data $K$ provides much better results than a single exponential function, even if $a_{K} \ll c_{K}$.

\section{Temperature influence}

From the viscosity curves and the resulting curves of $n$ and $K$, a strong temperature influence is obvious. To improve the

TABLE I. Identified parameters resulting from the curve fitting process to the reconstructed points $n$ and $K$

\begin{tabular}{lccc}
\hline \multirow{2}{*}{$\begin{array}{l}\text { Power law } \\
\text { parameters }\end{array}$} & $\begin{array}{c}\text { Identified } \\
\text { parameters }\end{array}$ & $T_{0}=20^{\circ} \mathrm{C}$ & $T_{0}=25^{\circ} \mathrm{C}$ \\
\cline { 3 - 4 }$n$ & $a_{\mathrm{n}}(1 / \mathrm{s})$ & $2.33 \times 10^{-4}$ & $3.27 \times 10^{-4}$ \\
$K$ & $b_{\mathrm{n}}(\mathrm{)})$ & 0.384 & 0.359 \\
& $a_{\mathrm{K}}\left(\mathrm{Pa} \mathrm{s}^{n}\right)$ & $3.08 \times 10^{-8}$ & $1.41 \times 10^{-10}$ \\
& $b_{\mathrm{K}}(1 / \mathrm{s})$ & $1.79 \times 10^{-2}$ & $3.06 \times 10^{-2}$ \\
& $\left.c_{\mathrm{K}}(\mathrm{Pa} \mathrm{s})^{n}\right)$ & 430 & 545 \\
& $d_{\mathrm{K}}(1 / \mathrm{s})$ & $2.68 \times 10^{-3}$ & $3.95 \times 10^{-3}$ \\
\hline
\end{tabular}

current definition of the power law by considering this temperature dependence, the optimization problem expressed by Eq. 7 has been solved. With a mean determination coefficient $R_{\mathrm{d}}^{2}=0.9987 \pm 0.002$, computed parameters $a_{T_{\text {ref } \rightarrow T_{i}}}$ and $b_{T_{\text {ref }} \rightarrow T_{i}}$ are represented in Figure 8 by circular markers.

The choice of the $X$-axis highlights that both shift factors can be identified as an Arrhenius law. Hence, these shift factors are given by

$$
\begin{aligned}
& a_{T_{\text {ref } \rightarrow T}}=\exp \left(\frac{E_{a}}{R_{\text {gas }}}\left(\frac{1}{T}-\frac{1}{T_{\text {ref }}}\right)\right) \\
& b_{T_{\text {ref } \rightarrow T}}=\exp \left(\frac{-E_{b}}{R_{\text {gas }}}\left(\frac{1}{T}-\frac{1}{T_{\text {ref }}}\right)\right)
\end{aligned}
$$

These equations ensure that $a_{T_{\text {ref } \rightarrow T}}=1$ and $b_{T_{\text {ref } \rightarrow T}}$ when $T=T_{\text {ref. }}$ A last optimization problem has been solved in order to fit the curves described by Eqs. 12 and 13 to the data displayed in Figure 8. This least-squares regression leads to the identification of the parameters:

$$
\begin{aligned}
& E_{a}=5.70 \times 10^{4} \mathrm{~J} / \mathrm{mol} \\
& E_{b}=7.75 \times 10^{4} \mathrm{~J} / \mathrm{mol}
\end{aligned}
$$

where the normalized root mean square error (NRMSE) is 0.974 for $a_{T_{\text {ref } \rightarrow T}}$ and 0.941 for $b_{T_{\text {ref } \rightarrow T} \text {. The fitted functions }}$ $a_{T_{\text {ref } \rightarrow T}}$ and $b_{T_{\text {ref } \rightarrow T}}$ are plotted with straight lines in Figure 8 . By combining the double shifting proposed in Eq. 6 with the power law (1), viscosity $\eta$ can be computed as a function of shear rate, time and temperature, for a given $T_{\text {ref, }}$ and writes

$$
\eta\left(\dot{\gamma}, a_{T_{\text {ref } \rightarrow T}} t, T\right)=b_{T_{\text {ref } \rightarrow T}} K\left(t, T_{\text {ref }}\right) \dot{\gamma}^{n\left(t, T_{\text {ref }}\right)} 1
$$

where parameters $n$ and $K$ are

$$
\begin{gathered}
n\left(a_{T_{\text {ref } \rightarrow T}} t, T\right)=n\left(t, T_{\text {ref }}\right) \\
K\left(a_{T_{\text {ref } \rightarrow T}} t, T\right)=b_{T_{\text {ref } \rightarrow T} K\left(t, T_{\text {ref }}\right)}
\end{gathered}
$$

To assess the identification of this complete model, a validation step is fundamental. Therefore, Eq. 16 has been applied for the same temperatures and shear rate than in Figure 5A. The results are plotted with solid lines in Figure 9, whereas the dashed lines represent the data acquired during the rheological study.

\section{Online viscosity estimation}

The online viscosity estimation has been performed for seven different experiments on the injection device. The corresponding testing conditions are gathered in Table II, especially the storage of the sheath is given. The temperature set point is reached due to the heat exchanger (Figure $3 \mathrm{~A}$ ). When there is no cancellous insert inside the phantom vertebra, the cement flow is free at the outlet of the conduit. 


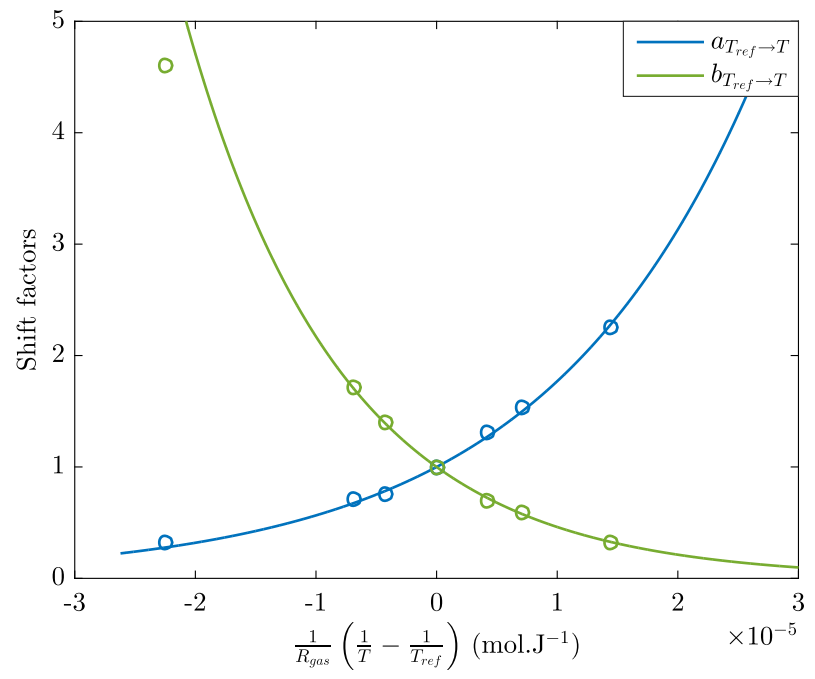

FIGURE 8. Results of the computation of parameters $a_{T_{\text {ref }} \rightarrow T_{i}}$ and $b_{T_{\text {ref }} \rightarrow T_{1}}$ (circular markers) that can both be fitted by an Arrhenius law (solid lines) where the temperatures $T_{\text {ref }}$ and $T$ are expressed in Kelvin.

For the first two experiments, the parameter $K$ of the power law has been computed according to the method developed in the "Online viscosity estimation" section and plotted over time in Figure 10A. The rheological study has led to the computation of the parameter $K$ at the reference temperature $T_{\text {ref }}=20^{\circ} \mathrm{C}$ (Figure 7B). Based on Eq. 18, the theoretical curve of $K$ at the temperature of the first two experiments at $24^{\circ} \mathrm{C}$ has been computed and overlaid in Figure 10A with a purple dashed line.

Besides the validation of the online viscosity computation, other experiments have been conducted in order to understand the respective roles played by the active and the passive heat exchangers. Therefore, Figure 10B gathers the curves of the viscosity estimation for experiments 3-7.

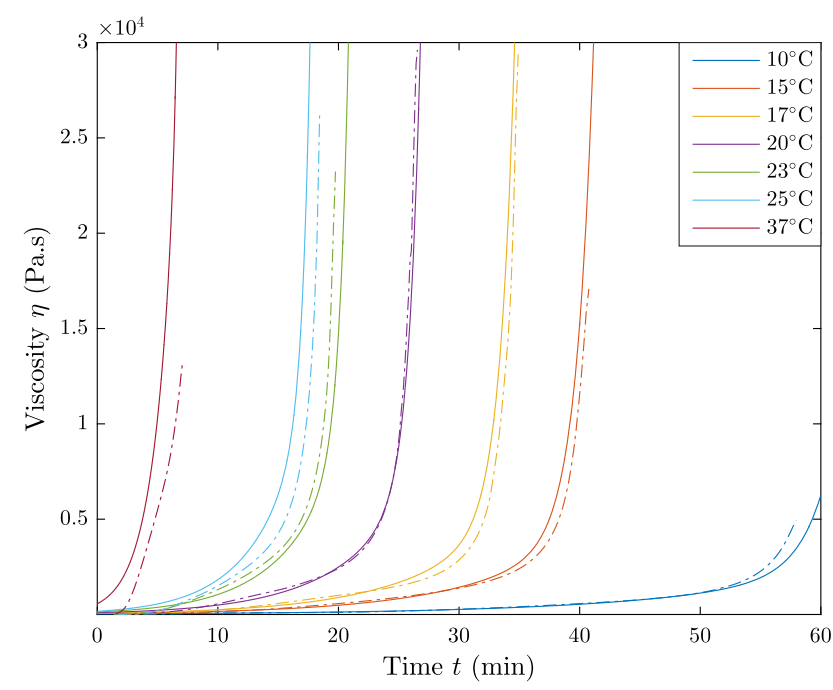

FIGURE 9. Cross validation step for the improved power law model where the dashed lines result from the rheological study and the solid lines result from the identified model.

\section{DISCUSSION}

\section{Rheological study}

As expected, Figure 5A shows that the cooler the cement, the longer the curing time. Indeed, at $37^{\circ} \mathrm{C}$, the bone cement Osteopal ${ }^{\circledR} \mathrm{V}$ needs less than $5 \mathrm{~min}$ to reach $5000 \mathrm{~Pa} \cdot \mathrm{s}$, against approximately $60 \mathrm{~min}$ at $10^{\circ} \mathrm{C}$. Moreover, $15 \mathrm{~min}$ after the mixing, a temperature difference of only $6^{\circ} \mathrm{C}$ (between 17 and $23^{\circ} \mathrm{C}$ ) generates almost a multiplication by four of the viscosity value. These observations demonstrate that the bone cement setting time can easily be increased by cooling down the cement of only a few degrees. This also shows that the cooling of bone cement kits inside a refrigerator prior to any percutaneous vertebroplasty increases the setting time.

Regarding Figures 5B,C, it can be noticed that the higher the shear rate, the lower the viscosity value. For instance, increasing the shear rate by one decade results in a viscosity difference of almost a decade after $10 \mathrm{~min}$. This confirms the shear-thinning behavior of acrylic bone cement Osteopal ${ }^{\circledR}$ V. Surprisingly, the end of the polymerization process seems to be superimposed for all frequencies at a given temperature. Hence, it seems challenging to increase the working phase beyond a certain time period (around $27 \mathrm{~min}$ at $20^{\circ} \mathrm{C}$ and $18 \mathrm{~min}$ at $25^{\circ} \mathrm{C}$ ) even if the sample is highly sheared, for instance, at $\dot{\gamma}=20 \times 2 \pi \approx 125 \mathrm{~s}$. The curves do not reach the same maximum viscosity value. This phenomenon is caused by the slippage of the bone cement during the experiments. Indeed, if the adherence between the rotating plate and the cement is not sufficient to transfer the shear stress to the rotor axis, the output measure is not significant.

The complete rheological study has only been conducted for the Osteopal ${ }^{\circledR} \mathrm{V}$ bone cement, which is exclusively used by our medical partners. However, the rheological properties and the shape of the viscosity evolution have also been analyzed for several other bone cements such as the CementoFixx-M and the CementoFixx-R from Optimed. As illustrated in Figure 11, their properties are very similar, which leads us to think that our methodology is applicable to all acrylic bone cements.

\section{Identification of the power law}

The identification of the power law starts with the computation of $n$ and $K$ parameters. According to Figure 7A, $n$ decreases slightly over time and is significantly below 1 confirming the shear-thinning behavior. $K$ is the parameter that is directly related to a zero- or low-shear viscosity, as inside the vertebra. Figure 7B illustrates that $K$ is almost multiplied by 5 within the time of a vertebroplasty procedure, for instance, from 7 to $15 \mathrm{~min}$.

By considering the temperature dependence, a complete model has been expressed by Eq. 16 and exploited in Figure 9. This figure shows that the model described by Eq. 16 provides an accurate representation of the bone cement viscosity. The NRMSE between the predicted values and the rheological data reaches 0.832 . However, some small shifts are observable. They are mainly due to the identification errors of the Arrhenius laws of $a_{T_{\text {ref } \rightarrow T}}$ and $b_{T_{\text {ref } \rightarrow T}}$ parameters (see Figure 8) that fit the experimental data. 
TABLE II. Testing conditions of the conducted experiments

\begin{tabular}{lccc}
\hline $\begin{array}{c}\text { Experiment } \\
\text { number }\end{array}$ & $\begin{array}{c}\text { Sheath } \\
\text { storage }\end{array}$ & $\begin{array}{c}\text { Temperature } \\
\text { set point }\left({ }^{\circ} \mathrm{C}\right)\end{array}$ & $\begin{array}{c}\text { Cancellous } \\
\text { insert }\end{array}$ \\
\hline 1 & $T_{\mathrm{a}}$ & 24 & No \\
2 & $T_{\mathrm{a}}$ & 24 & Yes \\
3 & $T_{\mathrm{a}}$ & & No \\
4 & Fridge & 10 & No \\
5 & Fridge & & No \\
6 & Freezer & 40 & No \\
7 & Fridge & 40 & No \\
\hline
\end{tabular}

These errors are reflected and amplified in these final results. One can especially notice that the shift between the experimental data (dashed lines) and the output of our model (solid lines) can be matched up with the sign of the error between the experimental data and the fitted curves in Figure 8.

\section{Online viscosity estimation}

For the first experiment, the flow at the cannula outlet is free which means that the bone cement flows out at atmospheric
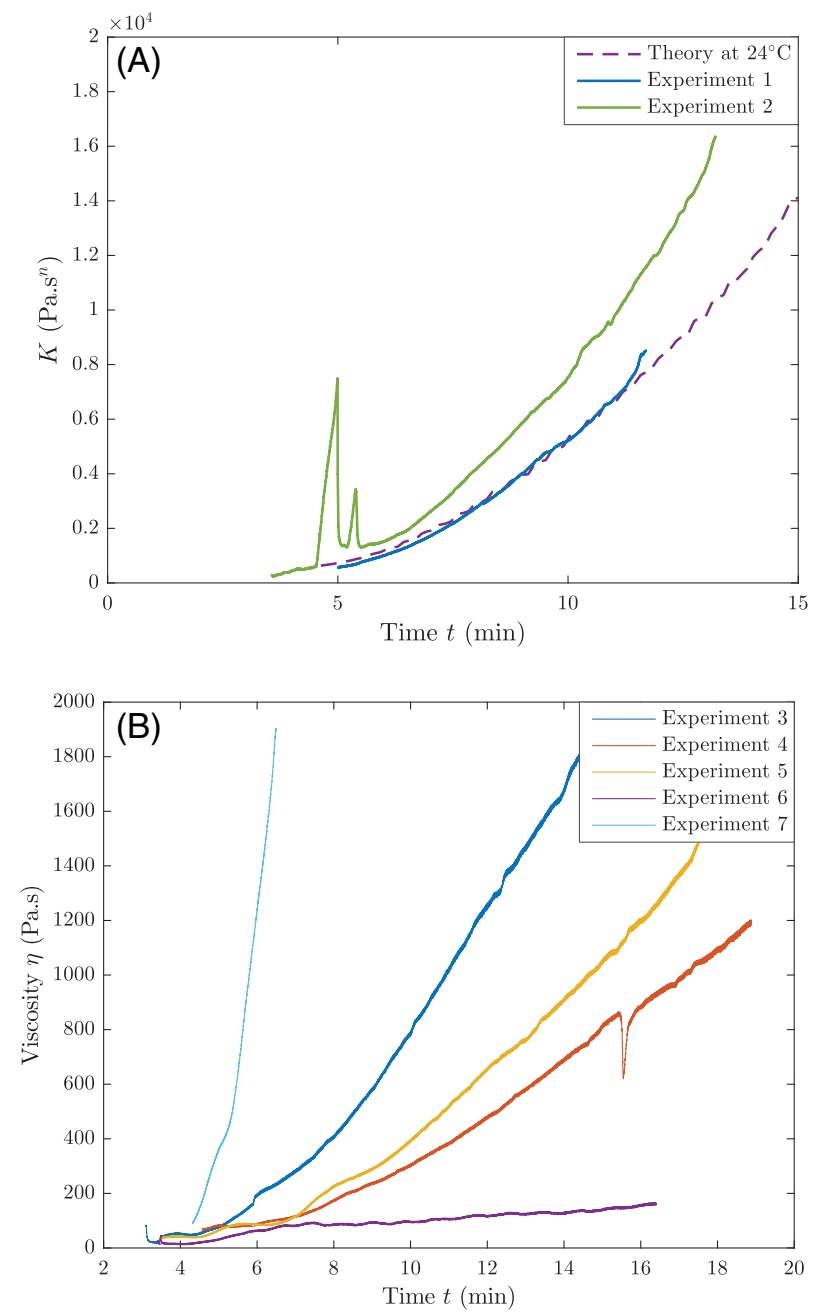

FIGURE 10. Evolution of $(\mathrm{A})$ the parameter $K$ of the power law for two experiments and $(B)$ the viscosity $\eta$ for five experiments. pressure. This corresponds to one of the hypothesis considered by the computation method. One can remark that the blue curve corresponding to experiment 1 overlaps the theoretical curve (purple curve). This validates the viscosity computation under the assumption that the cement flows out at atmospheric pressure at the outlet of the cannula. For the second experiment, the bone cement was injected inside a phantom vertebra filled with a cancellous inside. This simulates the interactions that may occur during the injection of bone cement into a real vertebra, where the cement spread is more complex. Two sharp peaks on the curve at instants between 4 and 6 min are noticeable. They correspond to the formation of a plug at the end of the needle, which is a common phenomenon occurring during vertebroplasty procedures. The increasing shift between the green and the purple curve clearly demonstrates that the intravertebral pressure differs from the atmospheric one and increases during the injection. In the future, a pressure sensor will be added on the pipe, providing $P_{\text {sens. }}$ Then the pressure drop will be computed as $\Delta P(t)=F(t) /\left(\pi R_{s}^{2}\right)-P_{\text {sens }}$.

In Figure $10 \mathrm{~B}$, the blue curve corresponding to experiment 3 represents the viscosity evolution without any control of the bone cement temperature. It can be considered as the reference viscosity curve illustrating the viscosity evolution during a normal percutaneous vertebroplasty procedure. In the curve associated to experiment 4 , the sudden drop in viscosity is probably due to the flow of an air bubble inside the syringe. Despite the fact that the copper block was set at $10^{\circ} \mathrm{C}$ for experiment 4 , testing conditions for curves 4 and 5 are very close. Compared to the reference curve, note that a cold storage of the sheath decreases significantly its viscosity. On top of that, for experiment 4, a low temperature set point $\left(10^{\circ} \mathrm{C}\right)$ helps to intensify this decrease of the viscosity rate and, thus, of the polymerization rate. However, the sheath should not be stored at a too low temperature, for example, inside the freezer, otherwise, the polymerization reaction can almost freeze and even an important heat input through the thermal exchanger may not reactivate the

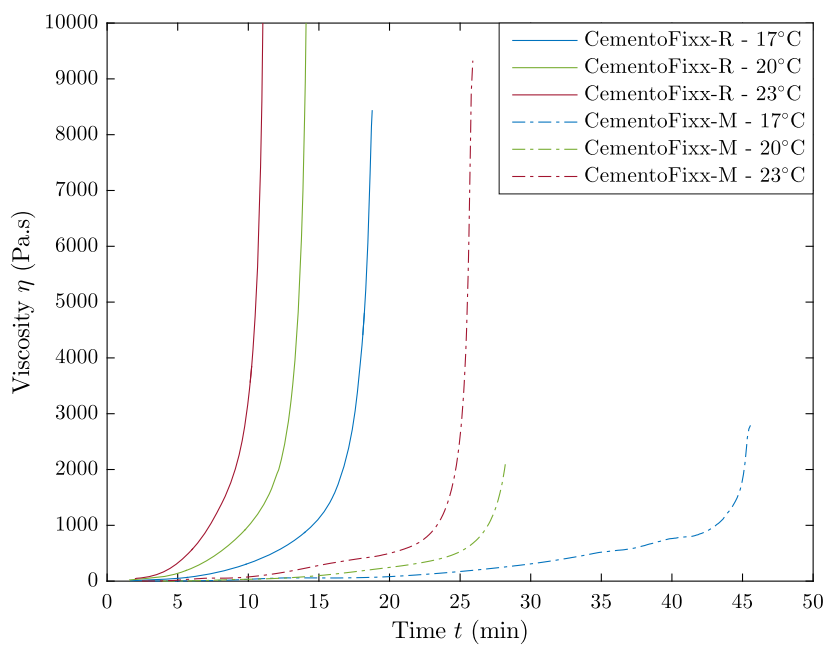

FIGURE 11. Evolution of viscosity along time from mixing at $2 \pi / \mathrm{s}$ for three temperatures for CementoFixx $\mathrm{M}$ and CementoFixx $\mathrm{R}$ bone cements. 
chemical reaction. This fact is sustained by experiment 6 during which the sheath was in a freezer prior to the experiment. While the copper block was set at $40^{\circ} \mathrm{C}$, the measured viscosity does not exceed $200 \mathrm{~Pa}$ s even after $16 \mathrm{~min}$. In such a case, since the viscosity remains low, the risk of bone cement leakage is extremely high. Therefore, if the syringe holder is stored in a suitable temperature range, as for experiment 7 , the polymerization reaction can easily be accelerated and the bone cement viscosity increased by heating it through the active temperature control block.

\section{CONCLUSION}

Vertebroplasty is a common minimally invasive procedure allowing to successfully consolidate painful vertebral fractures. In this article, a complete rheological study has been proposed in order to model the behavior of Osteopal ${ }^{\circledR} \mathrm{V}$ bone, and more generally PMMA cements during their polymerization. The study focuses on the parameters influencing the cement curing, such as shear rate, time and temperature. Experiments have been carried out on a rotational rheometer from the end of the cement mixing until the end of its hardening, both at an imposed temperature and shear rate. Based on these measurements, a constitutive model has been identified, which expresses the shear-thinning, temporal, and thermal properties of the cement. The validation procedure allows to assess the accuracy of the identified parameters. In addition, other experiments have been conducted in different testing conditions in order to validate the online estimation of PMMA cement viscosity. To this end, the temperaturecontrolled bone cement has been forced to flow through the conduit of a purposely designed injection device. The measurement of the flow rate and of the pressure over time, provided by an appropriate instrumentation, has been used to determine online the viscosity evolution. According to our experiments and in comparison with the rheological study, viscosity computation has provided reliable results. The presented outcomes show that the temperature control through a heat exchanger, as well as the initial thermal conditions, influences the evolution of the acrylic bone cement viscosity. The proposed viscosity estimation model will further be used for the online control of the bone cement viscosity during its injection.

Despite an extensive use of acrylic bone cements for vertebroplasty procedures because of their mechanical properties, new bone cements are available, such as calcium phosphate cements usually preferred for young patients for biocompatibility reasons. Even if the rheological study described here has been performed for Osteopal ${ }^{\circledR} \mathrm{V}$ cement, the approach proposed in this article remains largely valid, as it is independent of the cement composition and takes into account the shear-thinning, the temporal, and the thermal properties. As a future work, the hypothesis concerning the pressure at the outlet of the trocar should be further investigated and relaxed. Indeed, a poor bone cement flow inside a vertebra can lead to the accumulation of cement at the exit of the cannula and to a strong pressure increase that should be taken into account.

\section{ACKNOWLEDGMENT}

The authors kindly thank François Schmitt from the ICube Laboratory for his support concerning the design of the mechanical system.

\section{REFERENCES}

1. Gangi A, Sabharwal T, Irani FG, Buy X, Morales JP, Adam A. Qual ity assurance guidelines for percutaneous vertebroplasty. Cardio vasc Intervent Radiol 2006;29(2):173 178.

2. Galibert $P$, Deramond $H$, Rosat $P$, Le Gars D. Preliminary note on the treatment of vertebral angioma by percutaneous acrylic verteb roplasty. Neurochirurgie 1987;33:166 168.

3. Clark W, Bird P, Gonski P, Diamond TH, Smerdely P, McNeil HP, Schlaphoff G, Bryant C, Barnes E, Gebski V. Safety and efficacy of vertebroplasty for acute painful osteoporotic fractures (VAPOUR): A multicentre, randomised, double blind, placebo controlled trial. Lancet 2016;388(10052):1408 1416.

4. Anselmetti GC, Corrao G, Della Monica P, Tartaglia V, Manca A, Eminefendic H, Russo F, Tosetti I, Regge D. Pain relief following percutaneous vertebroplasty: Results of a series of 283 consecutive patients treated in a single institution. Cardiovasc Intervent Radiol 2007;30(3):441 447.

5. McGraw JK, Lippert JA, Minkus KD, Rami PM, Davis TM, Budzik RF. Prospective evaluation of pain relief in 100 patients undergoing per cutaneous vertebroplasty: Results and follow up. J Vasc Interv Radiol. 2002;13(9, Part 1):883 886.

6. Chang X, Lv Y F, Chen B, Li H Y, Han X B, Yang K, Zhang W, Zhou Y, Li C Q. Vertebroplasty versus kyphoplasty in osteoporotic vertebral compression fracture: A meta analysis of prospective comparative studies. Int Orthop 2015;39(3):491 500.

7. Heini FP, Wälchli B, Berlemann U. Percutaneous transpedicular ver tebroplasty with PMMA: Operative technique and early results. Eur Spine J 2000;9(5):445 450.

8. Eck JC, Nachtigall D, Humphreys SC, Hodges SD. Comparison of vertebroplasty and balloon kyphoplasty for treatment of vertebral compression fractures: A meta analysis of the literature. Spine J 2008;8(3):488 497.

9. Baroud G. Method and Apparatus for Monitoring and/or Controlling the Curing of Cements used in Medical Procedures. Patent US 20140009173 A1, 2014.

10. N Lepoutre, GI Bara, L Meylheuc, F Schmitt, L Barbé and B Bayle, Design and control of a thermal device for bone cement injection. In: 2016 6th IEEE International Conference on Biomedical Robotics and Biomechatronics (BioRob); 2016. pp. 508513.

11. N Lepoutre, R Aleluia Porto, L Meylheuc, GI Bara, F Schmitt, $\mathrm{L}$ Barbé and B Bayle. Robotically assisted injection of orthopedic cement: System design, control and modeling. In: 2016 European Control Conference (ECC); 2016. pp. 21272132.

12. Alenezi S, Jerban S, Elkoun S. Importance of the PMMA viscoelas tic rheology on the reduction of the leakage risk during osteopo rotic bone augmentation: A numerical leakage model through a porous media. J Mech Behav Biomed Mater 2017;65:29 41.

13. Kolmeder S, Lion A, Landgraf R, Ihlemann J. Thermophysical prop erties and material modelling of acrylic bone cements used in ver tebroplasty. J Thermal Anal Calorim 2011;105:705 718.

14. Rodrigues DC, Gilbert JL, Hasenwinkel JM. Pseudoplasticity and setting properties of two solution bone cement containing poly(methyl methacrylate) microspheres and nanospheres for kyphoplasty and vertebroplasty. J.Biomed Mater Res B: Appl Bio mater 2009;91B(1):248 256.

15. Baroud G, Samara M, Steffen T. Influence of mixing method on the cement temperature mixing time history and doughing time of three acrylic cements for vertebroplasty. J Biomed Mater Res B: Appl Biomater 2004;68B(1):112 116.

16. Krause WR, Miller J, Ng P. The viscosity of acrylic bone cements. J Biomed Mater Res 1982;16(3):219 243.

17. Lewis G, Carroll M. Rheological properties of acrylic bone cement during curing and the role of the size of the powder particles. J Biomed Mater Res 2002;63(2):191 199.

18. Farrar DF, Rose J. Rheological properties of PMMA bone cements during curing. Biomaterials 2001;22(22):3005 3013. 
19. Nicholas M, Waters M, Holford K, Adusei G. Analysis of rheological properties of bone cements. J Mater Sci Mater Med 2007;18:1407 1412.

20. Sullivan SJL, Topoleski LDT. Influence of initial component temper ature on the apparent viscosity and handling characteristics of acrylic (PMMA) bone cement. J Biomed Mater Res B: Appl Bioma ter 2007;81B(1):224 230.

21. Widmer Soyka RP, López A, Persson C, Cristofolini L, Ferguson SJ. Numerical description and experimental validation of a rheology model for non Newtonian fluid flow in cancellous bone. $\mathrm{J}$ Mech Behav Biomed Mater 2013;27:43 53.

22. Kolmeder S, Lion A. Characterisation and modelling rheological properties of acrylic bone cement during application. Mech Res Commun 2013;48:93 99.

23. Lewis G. Viscoelastic properties of injectable bone cements for orthopaedic applications: State of the art review. J Biomed Mater Res B: Appl Biomater 2011;98B(1):171 191.

24. Zderic I, Steinmetz $P$, Windolf $M$, Richards RG, Boger A, Gueorguiev B. Bone cement flow analysis by stepwise injection through medical cannulas. Med Eng Phys 2016;38(12):1434 1438.

25. Bohner M, Gasser B, Baroud G, Heini P. Theoretical and experimental model to describe the injection of a polymethylmethacrylate cement into a porous structure. Biomaterials 2003;24(16):2721 2730.

26. Ostwald W. Ueber die Geschwindigkeitsfunktion der Viskosität dis perser Systeme. II. Colloid Polym Sci 1925;36(2):99 117

27. Carreau PJ. Rheological equations from molecular network theo ries. Trans Soc Rheol 1972;16:99 127.
28. Yasuda K. Investigation of the Analogies Between Viscometric and Linear Viscoelastic Properties of Polystyrene Fluids. Cambridge, MA: Department of Chemical Engineering, Massachusetts Institute of Technology; 1979.

29. Rusu MC, Ibanescu C, Cameliu Ichim I, Riess G, Popa M, Rusu D, Rusu M. Radiopaque acrylic bone cements with bromine containing monomer. J Appl Polym Sci 2009;111(5):2493 2506

30. Bird RB, Amstrong RC, Hassager O. Dynamics of Polymeric Liquids, Volume 1: Fluid Mechanics. Hoboken, NJ: Wiley; 1987.

31. Dealy JM, Larson RG. Structure and Rheology of Molten Polymers. Munich, Germany: Carl Hanser Verlag GmbH \& Co. KG; 2006.

32. Boger A, Wheeler K, Schenk B, Heini P. Clinical investigations of polymethylmethacrylate cement viscosity during vertebroplasty and related in vitro measurements. Eur Spine J 2009;18: 12721278.

33. Kühn K D. PMMA Cements Composition and Chemistry, Berlin: Springer; 2013.

34. Al Hadithi TSR, Barnes HA, Walters K. The relationship between the linear (oscillatory) and nonlinear (steady state) flow properties of a series of polymer and colloidal systems. Colloid Polym Sci 1992; 270(1):40 46 .

35. Lian Z, Chui C K, Teoh S H. A biomechanical model for real time simulation of PMMA injection with haptics. Comput Biol Med 2008; 38(3):304 312

36. Osswald T, Rudolph N. Polymer Rheology Fundamentals and Appli cations. Munich, Germany: Carl Hanser Verlag GmbH \& Co. KG; 2014 